\title{
Combined Intacs SK and Corneal Collagen Cross-linking for the Treatment of Keratoconus
}

\author{
Ramez Barbara, Hanna Garzozi, Adel Barbara
}

\begin{abstract}
Purpose: To evaluate the efficacy of the combined treatment of Intacs SK (S evere keratoconus) and corneal collagen crosslinking in the management of advanced keratoconus (KC).
\end{abstract}

Setting: P rivate laser center, Haifa, Israel. Affiliated to Hadassah Hospital, J erusalem.

Methods: This is a retrospective study. Intacs SK were implanted using manual technique in eyes with moderate-tosevere keratoconus followed by collagen corneal cross-linking (CXL). Evaluation included uncorrected visual acuity (UCVA), best spectacle corrected visual acuity (BSCVA), manifest refraction, slit-lamp examination and corneal topography. Ocular response analyzer (ORA) was used to assess the corneal hysteresis $(\mathrm{CH})$ and the corneal resistance factor ( $C R F)$.

Results: We report on improvement of the UCVA, BSCVA, decrease in myopia, astigmatism and keratometry readings. No significant change in $\mathrm{CRF}$ or $\mathrm{CH}$ was noted.

Conclusion: The combined treatment of Intacs SK and corneal $C X L$ for the treatment of advanced keratoconus is safe and effective. The combined treatment resulted in improved UCVA, BSCVA, keratometry readings and regularization of the topography but no significant change in $\mathrm{CRF}$ and $\mathrm{HS}$.

Keywords: Keratoconus, Cornea, Intacs, Intacs SK, Collagen corneal cross-linking UVA, Corneal topography, Corneal biomechanics, Ocular response analyzer, Orbscan.

How to cite this article: Barbara R, Garzozi H, Barbara A. Combined Intacs SK and Corneal Collagen Cross-linking for the Treatment of Keratoconus. IntJ KeratE ct Cor Dis 2012;1(2): 109-116

\section{Source of support $\mathrm{Nil}$}

Conflict of interest: None declared

\section{INTRODUCTION}

$\mathrm{K}$ eratoconus $(\mathrm{KC})$ is an ectatic degenerative disease which causes protrusion and thinning of the cornea. As a result the corneal surface becomes irregular with consequent irregular astigmatism which cannot be corrected by glasses. Hence, contact lenses $(C L)$ are needed to improve the visual acuity (VA) but many patients suffering from $\mathrm{KC}$ cannot tolerate the $\mathrm{CL}$ due to the irregularity and protrusion of the cornea on the one hand and due to the atopic and allergic conjunctivitis that are often associated with the disease. The disease is usually progressive and in almost $20 \%$ of cases necessitates corneal grafting.

Intacs are intrastromal corneal ring segments approved by the Food and Drug Administration (FDA) for the correction of mild-to-moderate myopia. ${ }^{1}$ M oreover, they have been shown to be effective in treating $K C^{2-9}$ They improve the $\mathrm{VA}$ flatten and regularize the cornea by an arcshortening effect. ${ }^{10}$ Intacs severe keratoconus (SK) are a new design of intracorneal ring segments developed by Addition Technology Inc. They are indicated for the treatment of moderate-to-severe keratoconus (SK) with steep keratometric values $>55.00$ diopters (D). They are oval shaped rings with a diameter of $6 \mathrm{~mm}$ and thickness of 0.40 and $0.45 \mathrm{~mm} \cdot{ }^{11,12} \mathrm{~T}$ wo nomograms are used to determine the thickness of the intracorneal ring segment that is needed. The first is keratometry-based and the second is cylindricalbased (Table 1).

Table 1: The two nomograms: Keratometry and cylindrical-based used to decide the thickness of the Intacs SK to be implanted

\begin{tabular}{ccc}
\hline Segment thickness & Mean keratometry & Cylinder \\
\hline $400 \mu$ & $55-62$ & $<5 \mathrm{D}$ \\
$450 \mu$ & $>62$ & $>5 \mathrm{D}$ \\
\hline
\end{tabular}

Corneal collagen cross-linking ( $C X L)$ is a relatively new therapy using ultraviolet A (UVA) with a photosensitizer riboflavin to increase corneal stiffness. It has been shown that $C X L$ is effective in arresting the progression of keratoconus. $^{13}$

To our knowledge, there are no published reports on the combined treatment of Intacs SK and CXL for the treatment of moderate-to-severe keratoconus. We used Intacs SK because of their increased efficacy in advanced keratoconus. CXL was used to stabilize the cornea. Our hypothesis was that combining the two treatments would yield an additive effect. ${ }^{14}$

\section{PATIENTS AND METHODS}

This is a retrospective study of the combined treatment of Intacs SK and CXL for moderate-to-severe KC. The indications for treatment were (1) unsatisfactory VA with glasses, (2) contact lens (CL) intolerance, (3) progressive $\mathrm{KC}$ with clear cornea except one eye which had a superficial corneal scar. Data collected since J une 2008. Fifteen eyes had CXL treatment immediately after Intacs SK implantation and two eyes had CX L w eeks after Intacs SK implantation. In the latter case, the patient was diagnosed earlier with severe $K C$ and was scheduled for PK P and in his case we were not certain that the Intacs SK will improve the patient's vision significantly, so we postponed the CX L 
for a later datetill improvement in uncorrected visual acuity (UCVA) and best-spectacle corrected visual acuity (BSCV A) was evident. Our aim was to spare the patient the inconvenience and pain following $C X L$ until we were sure that the Intacs SK were effective in his case.

Three cases were treated bilaterally, in three eyes of the only one ring implanted and two eyes had asymmetric rings. The rest of the eyes had the Intacs SK $0.4 \mathrm{~mm}$ pair or $0.45 \mathrm{~mm}$ pair implanted.

$\mathrm{CRF}$ and $\mathrm{CH}$ were measured using the Reichert ocular response analyzer preoperatively and at each visit postoperatively.

\section{SURGICAL TECHNIQUE}

Seventeen eyes of 14 keratoconic patients had implantation of Intacs SK by the manual technique. Surgical procedure was performed by one surgeon $(A B)$ under topical anesthesia. Standard draping was performed. The eye was washed with polidine $4 \%$. The cornea was marked with the special Intacs SK marker and manual dissection was performed using the special dissector of Intacs SK (provided by the A ddition Technology). The incision was made along the steep axis at a depth of $80 \%$ of the corneal thickness as measured by pachymetry in the operation room. Pachymetry was done onto the incision site and on the hypothetical channels as marked by the special Intacs SK marker.

Dissection was performed using a channel guide in clockwise and counterclockwise directions. The Intacs SK segments were soaked in zymar $0.3 \%$, (gatifloxacin) and then inserted as planned in the channels. Sinskey hook was used to adjust the final position. The procedure was suture less. Immediately following the implantation of the rings the epithelium was removed from the central $8 \mathrm{~mm}$ of the cornea and the patient was seated. Riboflavin $0.1 \%$ combined with Dextran 20\% was instilled every 5 minutes for 30 minutes in corneas thicker than $400 \mu$. Riboflavin without dextran (isotonic solution) was used in cases where corneal thickness was less than $400 \mu$. Ultrasound pachymetry was performed after the removal of the epithelium and half an hour after instillation of riboflavin $0.1 \%$ of hypotonic riboflavin solution and treatment was performed only after the following:

1. Increase in corneal thickness at the thinnest point to more than $350 \mu$ without epithelium.

2. Appearance of strong yellow flare in the anterior chamber.

Speculum was inserted and the patient was asked to look into UVA (365-370 nm) light source $5 \mathrm{~mm}$ from the eye (UVX produced by Peschke $\mathrm{GmbH}$ ) with a light intensity of $3 \mathrm{~mW} / \mathrm{cm}^{2}$. During treatment, riboflavin was instilled every 5 minutes the eye and BSS every 3 minutes during the 30 minutes exposure of the cornea to the UVA. Riboflavin with and without dextran $20 \%$ were used as given pre- $\mathrm{CX}$ L treatment in accordance to corneal thickness. A therapeutic contact lens was inserted following the treatment till full epithelialization.

In two eyes the CXL was performed few weeks in the first case and few months in the second case after the insertion of the Intacs SK because we were not sure that Intacs SK implantation will yield a satisfactory improvement of the VA and we did not want to perform CXL immediately after the rings implantation as we did in the remaining 15 eyes. We wanted to spare the patients an unnecessary treatment in case failure of the rings to improve the $\mathrm{VA}$ to a satisfactory level to the patient.

Vigamox (moxifloxacin 0.3\%) antibiotics were prescribed for 1 month and FML was added for 2 weeks only following epithelial healing which occurred after 3 days.

There were no intraoperative complications. In two eyes a migration of one ring segment close to the incision site with protrusion occurred few months postoperatively. The segments were extracted, cut, soaked in polidine $4 \%$, washed with BSS and reinserted successfully with no further postoperative complications.

The mean thinnest corneal thickness was $407 \mu$ with a range between 291 and $493 \mu$.

\section{CASE REPORTS}

\section{Case 1}

A 31-year-old female was diagnosed with advanced KC in her right eye. She was $\mathrm{CL}$ intolerant and was scheduled for corneal transplant. Her UCV A was counting fingers from 1.5 meters and BSCVA was $6 / 15$ partial with manifest refraction of plano $-12.00 \times 50^{\circ}$. K minimum, $\mathrm{K}$ maximum and $K$ average were $48.87,55.5$ and 52 respectively with a central corneal thickness of $388 \mu$.

On the 18/05/2009 she had an Intacs SK $0.4 \mathrm{~mm}$ pair inserted followed immediately by CXL using the method mentioned above few months postoperatively one segment extruded partially. The segment was extracted, cut, soaked in polidine 4\%, washed with BSS and reinserted successfully with no further postoperative complications. Thirty-five months postoperatively, her UCV A was 6/18 and her BCV A was $6 / 6$ partial with manifest refraction of $+4 D=-4.0 C y l$ $* 40^{\circ} \mathrm{K}$ minimum, $\mathrm{K}$ maximum and $\mathrm{K}$ average were 47.12 , 49.75 and 48.37 respectively.

The combined treatment has resulted in improvement in her UCVA, BSCV A and reduction of the $K$ readings and the astigmatism (Figs 1 to 5 ). 


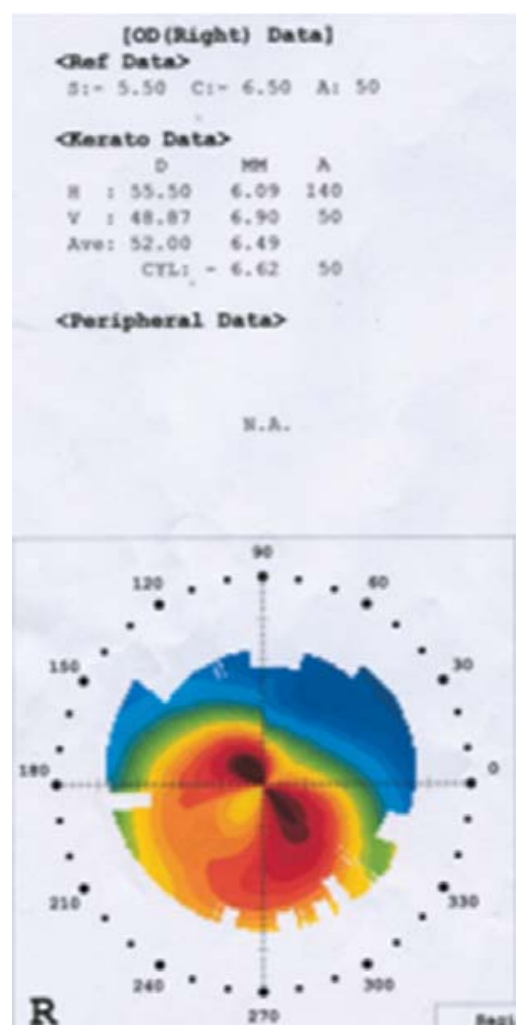

Fig. 1: Preoperative topography demonstrating $\mathrm{KC}$ with high K-values

\section{[os (Loft) Data]}

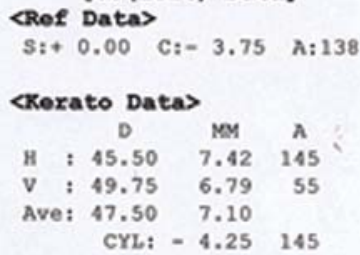

\section{<Poripheral Data>}

$\begin{array}{ccc} & \text { D } & \text { KM } \\ \text { H(145) } & 0.00 & 8056\end{array}$

CNT. $45.50 \quad 7.42$

(325) $0.00 \quad 8056$

v( 55) $\quad 0.00 \quad 8056$

CNT. $49.75 \quad 6.79$

(235) $0.00 \quad 8056$

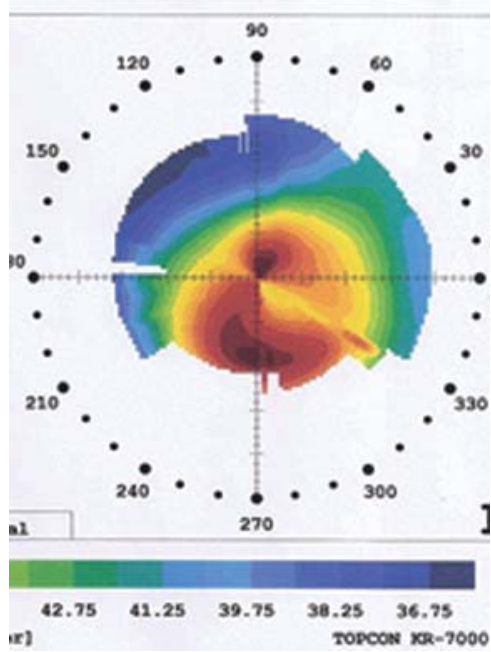

Fig. 2: Regularization of the corneal topography postoperatively and reduction in the K-values

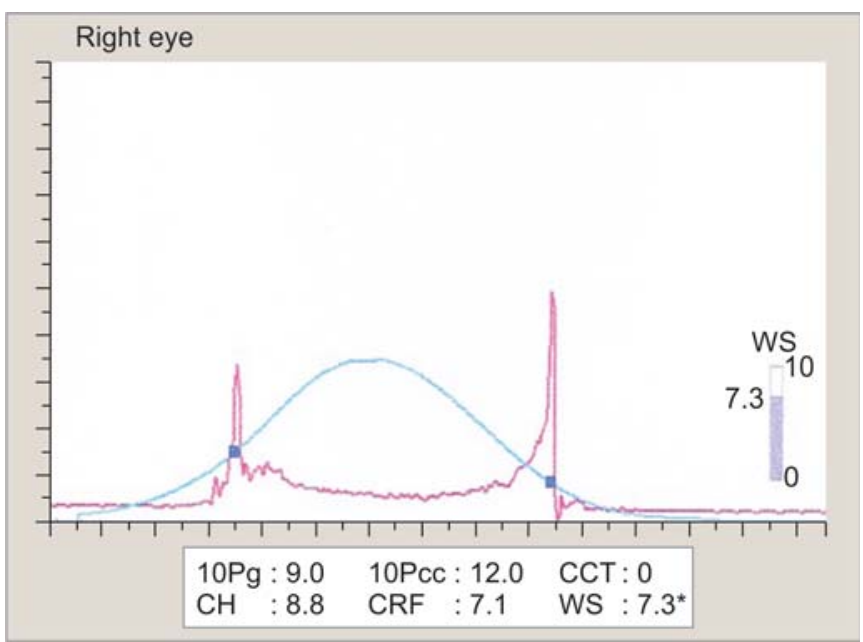

Fig. 3: Preoperative ORA

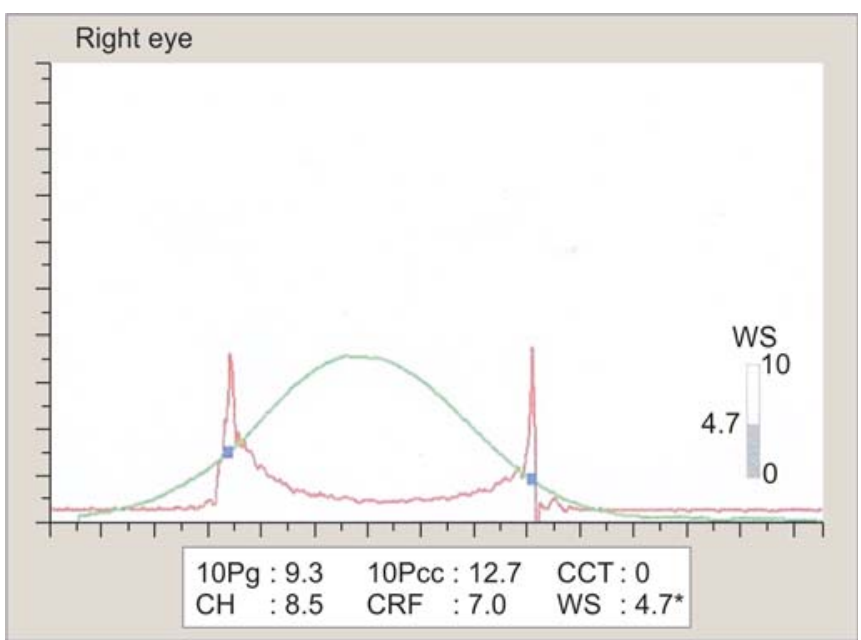

Fig. 4: Postoperative ORA

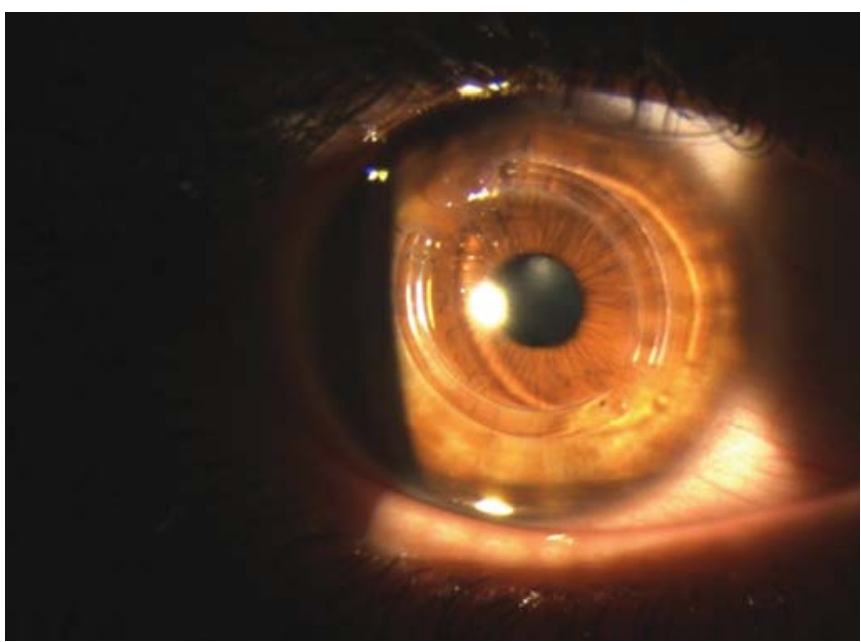

Fig. 5: Intacs SK in the cornea note the cut inferior edge of the temporal Intac SK in the LE

\section{Case 2}

A 27-year-old female, suffering from $K C$, with unsatisfactory VA with glasses and $\mathrm{CL}$ intolerant in her LE, Intacs SK were implanted on the 10th of February 2010 
followed by CXL, preoperatively UCV A and BSCVA were $1 / 120$ and $6 / 18$ respectively, the $K$ readings were: $K$ minimum, $K$ maximum and $K$ average $61.12,64.0$ and 62.62 respectively with a refraction of $+6.0 \mathrm{D}$ and $-11.0 \mathrm{D} \mathrm{Cy} / * 90$ and central corneal thickness of $420 \mu$.

Twenty-two months postoperatively: UCVA and BSCVA were $6 / 30$ and $6 / 15$ respectively with a refraction of $-0.5 \mathrm{D}$ and $-4.0 \mathrm{D}$ Cyl*130. The $\mathrm{K}$ readings were : $\mathrm{K}$ minimum, $\mathrm{K}$ maximum and $\mathrm{K}$ average $47.50,52.62$ and 49.87 respectively, a reduction of of more than $12 \mathrm{D}$ in the $\mathrm{K}$-values. BCVA with a soft keratoconus lens is $6 / 9$. Scarring was noted in the channels where Intacs SK were inserted, and this may explain the increased effect of Intacs SK combined with CXL (Figs 6 to 8).

\section{STATISTICAL ANALYSIS}

Statistical analysis was performed with SPSS softw are using (version 16, SPSS Inc). N ine parameters were analyzed preand postoperatively. The data was analyzed using the pair t-test for each parameter. Data is expressed as mean differences between pre and post for each parameter (Tables 2 and 3$)$

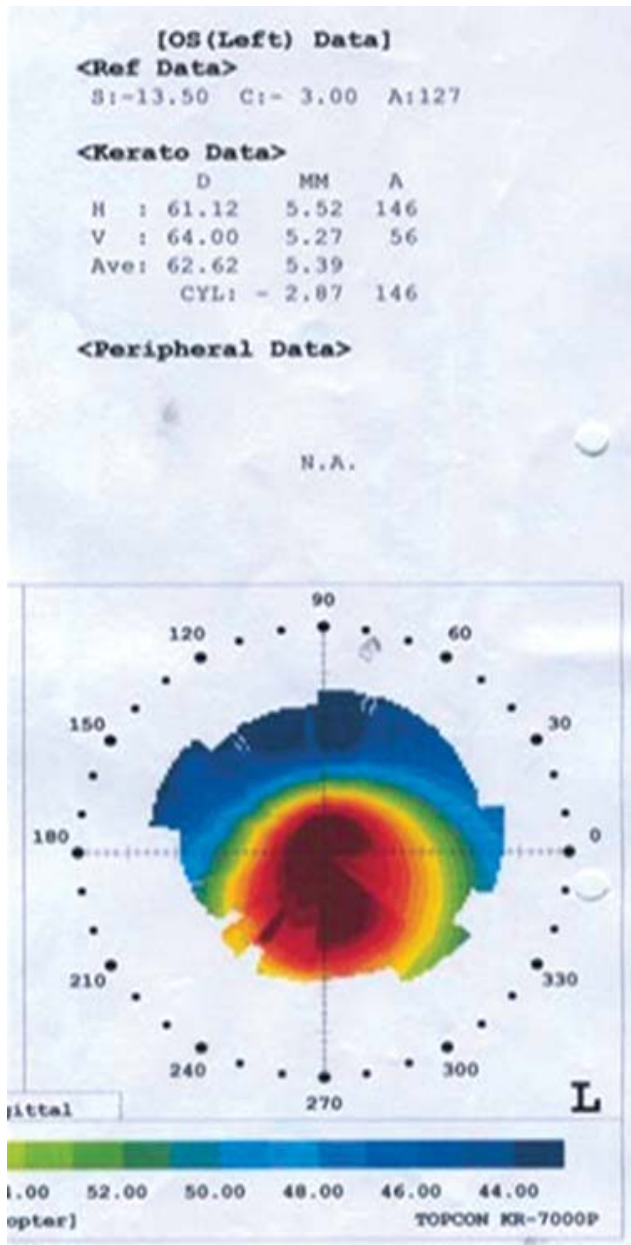

Fig. 6: Preoperative topography demonstrating KC with high K-values

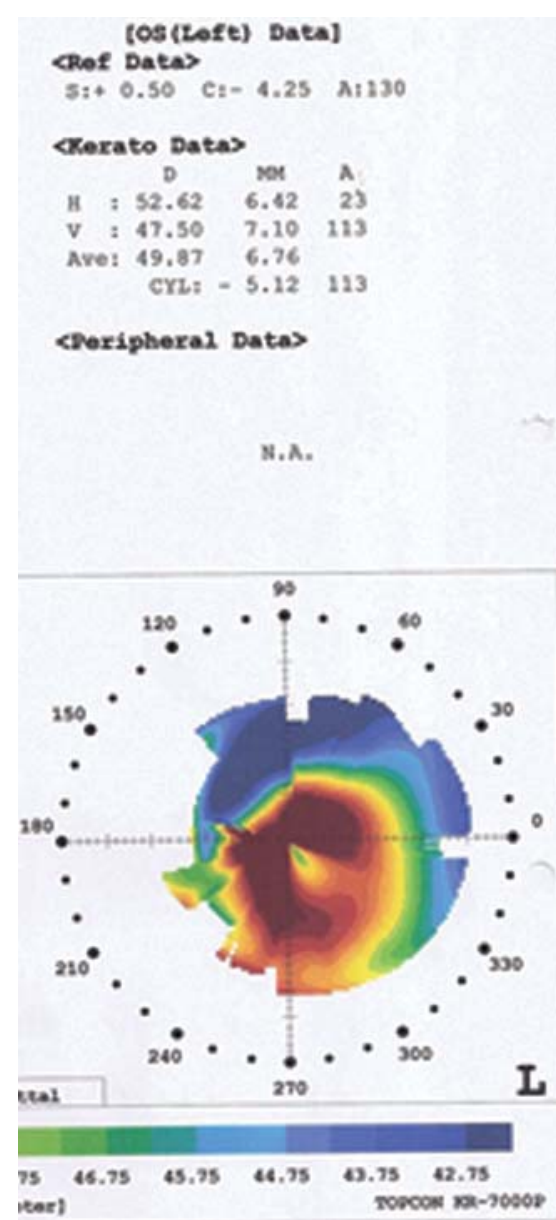

Fig. 7: Regularization of the corneal topography postoperatively and reduction in the $\mathrm{K}$-values

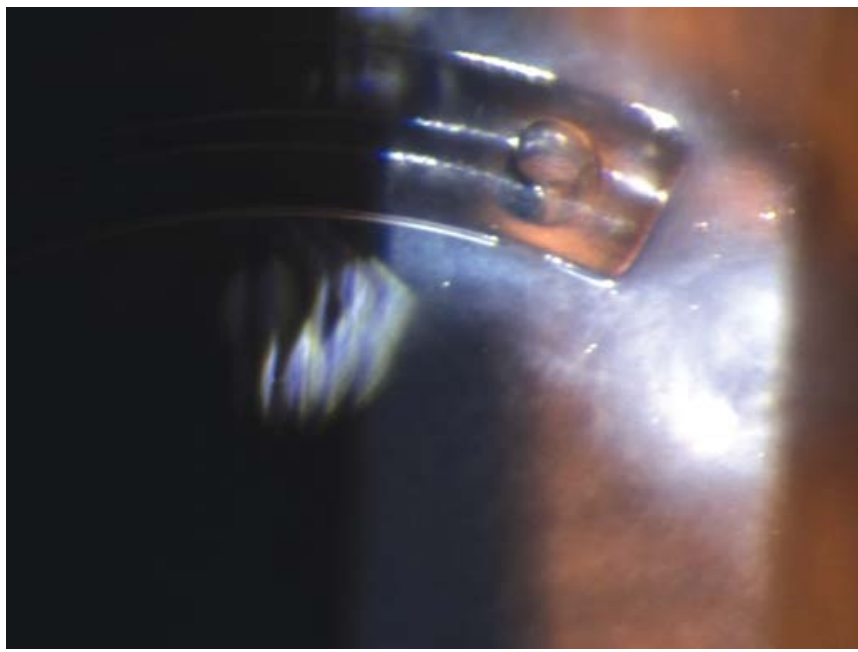

Fig. 8: Haze in the channel with the Intac SK, the haze (scaring) may explain the increased effect of the combined treatment

\section{RESULTS}

The study included 17 eyes of 14 patients 9 males and 5 females, The mean age was 25.7 years (range, 14-45 years). M ean follow-up (FU) was 15.4 months. FU ranged between 5 and 35 months (Tables 2 and 3 ). 
Combined Intacs SK and Corneal Collagen Cross-linking for the Treatment of Keratoconus

Table 2: Preoperative and postoperative mean values for the nine parameters

\begin{tabular}{|c|c|c|c|c|c|}
\hline & & & escriptive st & & \\
\hline & $\mathrm{N}$ & Minimum & Maximum & Mean & Std. deviation \\
\hline Age when operated & 17 & 14.00 & 45.00 & 25.7059 & 7.77628 \\
\hline Months to follow-up & 17 & 5 & 35 & 15.41 & 7.641 \\
\hline Pre-UCVA & 17 & 0.002 & 0.100 & 0.03393 & 0.038464 \\
\hline Post-UCVA & 17 & 0.017 & 0.600 & 0.23863 & 0.172902 \\
\hline Pre-SPH & 17 & -19.00 & 6.00 & -3.2500 & 6.72449 \\
\hline Post-SPH & 17 & -10.00 & 5.00 & 0.1471 & 3.77808 \\
\hline Pre-CYL & 17 & -12.00 & -3.50 & -9.7059 & 2.19416 \\
\hline Post-CYL & 17 & -8.00 & -1.50 & -4.6176 & 1.60594 \\
\hline Pre-BSCV & 17 & 0.025 & 0.630 & 0.28341 & 0.171498 \\
\hline Post-BSCV & 17 & 0.100 & 1.000 & 0.53641 & 0.241572 \\
\hline Pre- $K_{\max }$ & 15 & 46.50 & 72.21 & 59.8540 & 8.30478 \\
\hline Pre-K average & 15 & 45.50 & 70.50 & 56.8987 & 7.99119 \\
\hline Pre- $K_{\min }$ & 15 & 43.62 & 69.12 & 54.2540 & 7.84223 \\
\hline Post- $K_{\max }$ & 17 & 43.25 & 66.50 & 54.9841 & 7.96856 \\
\hline Post-K average & 17 & 42.87 & 63.50 & 52.2671 & 7.30470 \\
\hline Post- $K_{\min }$ & 17 & 40.10 & 60.50 & 49.7835 & 6.86875 \\
\hline $\mathrm{CCt}$ & 17 & 291.00 & 493.00 & 407.0000 & 55.37034 \\
\hline Pre-CRF & 17 & 5.00 & 8.20 & 6.6353 & 1.00557 \\
\hline Post-CRF & 16 & 5.00 & 10.90 & 6.9063 & 1.63808 \\
\hline Pre-CH & 17 & 5.50 & 11.20 & 8.3647 & 1.51201 \\
\hline Post-CH & 16 & 6.50 & 13.50 & 8.8812 & 1.90935 \\
\hline Valid N (listwise) & 15 & & & & \\
\hline
\end{tabular}

a. CXL: yes; UCVA: Uncorrected visual acuity; SPH: Sphere; CYL: Cylinder; BSCV: Best spectacle corrected visual acuity; ORA H: Ocular response analyzer corneal hysteresis; ORA RF: Ocular response analyzer corneal resistance factor; $K_{\max }$ : $\mathrm{K}$ maximum; $\mathrm{K}_{\min }: \mathrm{K}$ minimum

Table 3: Comparable results between the nine parameters measured using the t-test

\begin{tabular}{|c|c|c|c|c|c|c|c|c|c|}
\hline \multicolumn{10}{|c|}{ Paired sample test ${ }^{a}$} \\
\hline & & \multicolumn{5}{|c|}{ Paired differences } & \multirow[b]{3}{*}{$\mathrm{t}$} & \multirow[b]{3}{*}{ df } & \multirow[b]{3}{*}{$\begin{array}{c}\text { Sig } \\
\text { (2-tailed) }\end{array}$} \\
\hline & & \multirow[b]{2}{*}{ Mean } & \multirow[b]{2}{*}{$\begin{array}{l}\text { Std. } \\
\text { deviation }\end{array}$} & \multirow[b]{2}{*}{$\begin{array}{l}\text { Std. error } \\
\text { mean }\end{array}$} & \multicolumn{2}{|c|}{$\begin{array}{l}\text { 95\% confidence interval } \\
\text { of the difference }\end{array}$} & & & \\
\hline & & & & & Lower & Upper & & & \\
\hline Pair 1 & pre-UCYA-post-UCVA & -0.204702 & 0.163323 & 0.039612 & -0.288675 & -0.120729 & -5.168 & 16 & 0.000 \\
\hline Pair 2 & pre-SPH- post-SPH & -3.39706 & 4.42565 & 1.07338 & -5.67252 & -1.12160 & -3.165 & 16 & 0.006 \\
\hline Pair 3 & pre-CYL-post-CYL & -5.08824 & 2.23072 & 0.54103 & -6.23516 & -3.94131 & -9.405 & 16 & 0.000 \\
\hline Pair 4 & pre-BSCY-post-BSCY & -0.253000 & 0.217112 & 0.052657 & -0.364629 & -0.141371 & -4.805 & 16 & 0.000 \\
\hline $\begin{array}{l}\text { Pair } 5 \\
\text { Pair } 6\end{array}$ & $\begin{array}{l}\text { pre- } K_{\max }-\text { post- } K_{\text {max }} \\
\text { pre-K } \text { average- post- } K\end{array}$ & 5.05600 & 3.85403 & 0.99511 & 2.92171 & 7.19029 & 5.081 & 14 & 0.000 \\
\hline & average & 4.77600 & 3.65277 & 0.94314 & 2.75316 & 6.79884 & 5.064 & 14 & 0.000 \\
\hline Pair 7 & pre- $K_{\min }-$ post- $K_{\min }$ & 4.53933 & 3.79177 & 0.97903 & 2.43952 & 6.63914 & 4.637 & 14 & 0.000 \\
\hline Pair 8 & pre-CRF-post-CRF & -0.25625 & 1.59121 & 0.39780 & -1.10415 & 0.59165 & -0.644 & 15 & 0.529 \\
\hline Pair 9 & pre-CH-post-CH & -0.69375 & 1.79980 & 0.44995 & -1.65280 & 0.26530 & -1.542 & 15 & 0.144 \\
\hline
\end{tabular}

a. CXL: yes; UCVA: Uncorrected visual acuity; SPH: Sphere; CYL: Cylinder; BSCV: Best spectacle corrected visual acuity; ORA H: Ocular response analyzer corneal hysteresis; ORA RF: Ocular response analyzer corneal resistance factor; $K_{\max }$ : $K$ maximum; $\mathrm{K}_{\min }: \mathrm{K}$ minimum

\section{VISUAL ACUITY}

There was statistically significant improvement in the UCVA and BSCVA (decimal). The mean preoperative UCVA was 0.034 . The mean postoperative UCV A was 0.24 . The postoperative UCVA was significantly better than the preoperative UCVA $(p<0.01)$. The mean preoperative BSCVA was 0.28. The mean postoperative BSCVA was 0.54 . The mean preoperative BSCVA was significantly better than postoperatively $(p<0.001)$ (Fig. 9).

\section{Spherical and Cylindrical Change}

There was statistically significant reduction in the sphere and significant reduction in astigmatism $(p<0.001)$ with a mean reduction of 3.1 and $5.1 \mathrm{D}$ respectively (Fig. 10).

\section{Keratometry}

There was statistically significant change in the K minimum, $K$ maximum and $K$ average $(p<0.01)$ of $4.9,5.1$ and $4.5 D$ respectively (Fig. 11). 


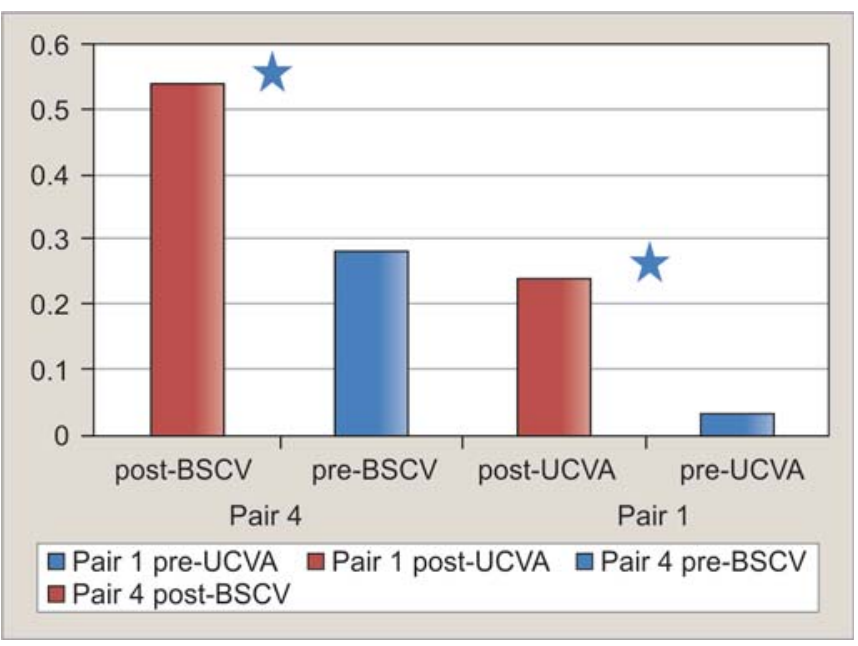

Fig. 9: Preoperative and postoperative UCVA and BSCVA

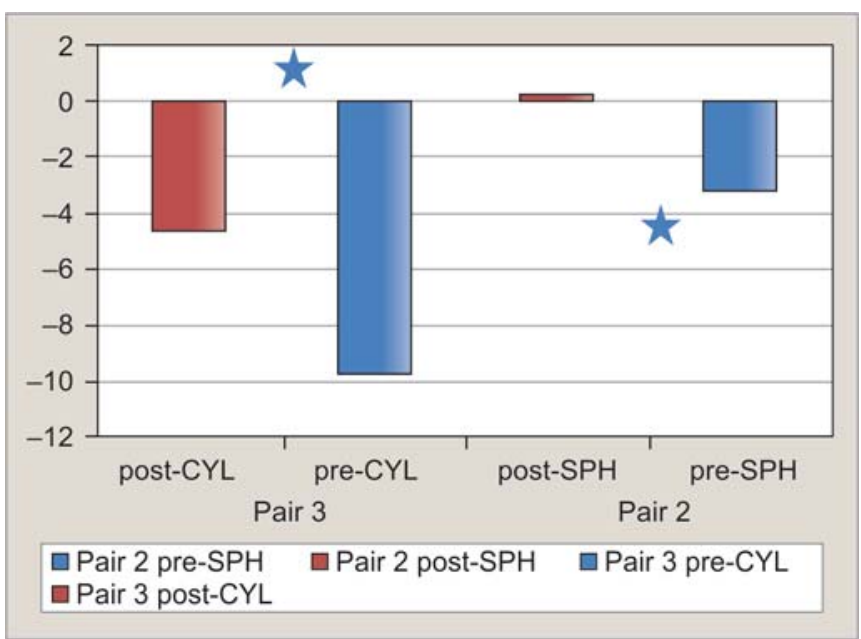

Fig. 10: Preoperative and postoperative sphere and cylinder values

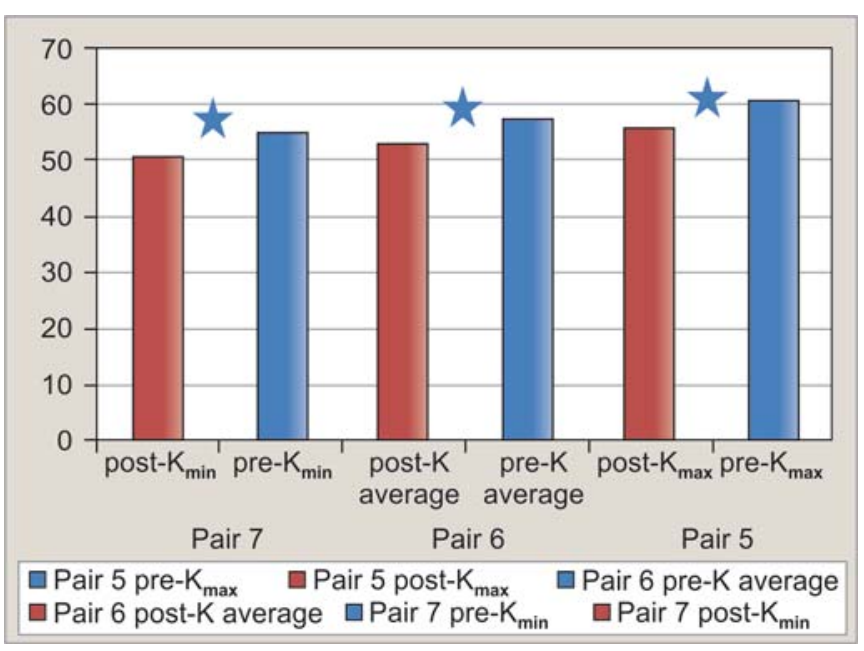

Fig. 11: Preoperative and postoperative keratometry readings

\section{Corneal Resistance Factor and Corneal Hysteresis}

No statistically significant change in corneal resistance factor (CRF) or corneal hysteresis (CH) $(p=0.529,0.144$ respectively) (Fig. 12).

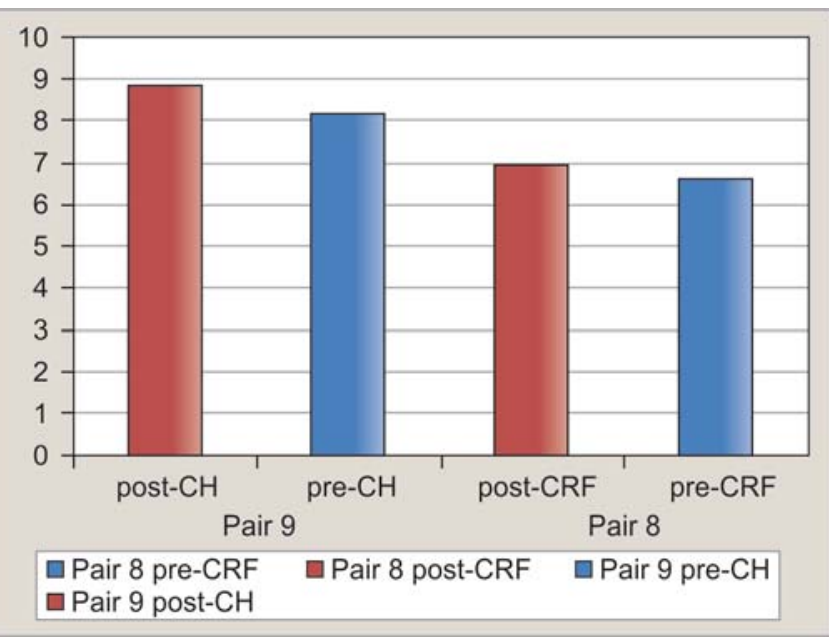

Fig. 12: Preoperative and postoperative $\mathrm{CRF}$ and $\mathrm{CH}$ values

\section{DISCUSSION}

This is a retrospective study on the effect of the combined treatment of Intacs SK and CXL in moderate to advanced $\mathrm{KC}$.

In 15 of the 17 eyes, the $C X L$ was performed immediately after the implantation of the Intacs SK. In two, CXL was performed few weeks in one eye and few months in another eye of another patient after Inatcs SK implantation and not immediately. These two patients suffered from severe KC and were scheduled for corneal transplant and we were not certain that the Intacs SK implantation would yield improvement in their vision significantly hence, we postponed the CX L till improvement in UCVA and BSCVA was evident. Our aim was to spare the patients the inconvenience and pain following $C X L$ until we were sure that the Intacs SK implantation was effective in their case.

It has demonstrated improvement in the U CVA, BSCVA, and reduction of myopia, astigmatism and keratometry readings.

Intacs SK corneal rings seem to be a compromise between the traditional Intacs with the $7 \mathrm{~mm}$ diameter and the Ferrara rings which are $5 \mathrm{~mm}$ in diameter. The effect is is proportional to thickness of the ring inversely proportional to the diameter of the ring. Intacs with the $7 \mathrm{~mm}$ diameter were demonstrated to have less effect on corneas with advanced keratoconus with a $\mathrm{K}$ reading of more than $55^{\circ} .{ }^{15}$

There is only on study in the literature regarding the use of Intacs SK in keratoconus by Sansanayudh et al. They reported on Intacs SK in 10 eyes with a minimum FU of 6 months. There was improvement in UCVA and BCVA and a decrease in high order aberrations and increased tolerance to $\mathrm{CL}$ tolerance postoperatively. ${ }^{12}$

Intrastromal corneal rings combined with $C X L$ are assumed to have an additive effect. This additive effect was demonstrated in few studies; Chan et al conducted a 
retrospective randomized study which demonstrated that the combination of CXL with Intacs led to better results than Intacs alone. They demonstrated a greater than 2-fold reduction in the combined group compared to Intacs alone group in steep and average K-values. They also assumed that the pooling of riboflavin into the intacs channels may produce increased effect of the CX L. ${ }^{16}$

Ertan and Colin referred to a presentation of $E I$ Cadarso on six pig eyes. Each pig was randomly assigned either $C X L$ alone or a combined Intacs and CXL. The eyes with the combined treatment demonstrated additional flattening compare to eyes receiving $C X L$ alone. The effect was maintained even when Intacs were withdrawn from the corneas in the combined group. ${ }^{17}$

$\mathrm{K}$ amburoglu et al also demonstrated the additive effect of the combined treatment. They treated cases of bilateral ectasia. The combined treatment of Intacs SK and CXL was compared to Intacs SK alone. The combined treatment was performed in an interval of 24 hours. In the immediate postoperative time, the Intacs SK group demonstrated satisfactory improvement in U CV A, BCV A and keratometry readings, however, these parameters had deteriorated 1 month postoperatively and the Intacs SK only group had to have CXL performed, regaining some of the improvement that was achieved with Intacs SK alone. ${ }^{18}$

Ertan et al compared the combined treatment of Intacs and transepithelial CX L to a matched group of Intacs alone on 25 eyes. They noted more improvement in the combined treatment modality, concluding that $\mathrm{CXL}$ has an additive effect. $^{14}$

The combination of Intacs and CX L is a logical approach as the corneal rings reshape and regularize the cornea while CXL stabilizes it. The logic behind the additive effect of Intacs SK and CXL is that Intacs are more effective in keratoconic corneas than normal corneas. The uncrosslinked keratoconic cornea is weaker than the cross-linked one and in the uncross-linked corneas the effect of rings is stronger. This hypothesis was confirmed by a recent study of Coskunseven et al. ${ }^{19} \mathrm{He}$ did a comparative study using intrastromal rings and $C X L$ in different sequence. The two groups were followed for $13 \pm 1$ month. The interval between treatments was $7 \pm 2$ months. The two groups demonstrated improvement in UCV A, BCV A, and decrease in mean spherical equivalent ( SE), cylinder and $\mathrm{K}$-values. Nevertheless, the group which had intrastromal rings followed by $C X L$ demonstrated more improvement in BCV A and decrease in mean SE and K-values compared to the other group. ${ }^{19}$

In our study, the patients had the two procedures at the same day to spare them the inconvenience of having two procedures done at two different occasions and save them days off work, pain and travel.
CRF and $\mathrm{CH}$ reflect the biomechanical characteristics of the cornea as measure by ocular response analyzer (ORA). $\mathrm{CRF}$ and $\mathrm{CH}$ are lower in keratoconic than normal corneas. $^{20-22}$ These values are supposed to increase after the combined treatment; nevertheless, as our results show they did not change significantly. These values do not reflect the clinical and topographic improvement achieved. ORA possess the sensitivity to detect keratoconus but lacks the specificity of detecting changes in these corneas at least with the software that we used, Reichert $L t d$, purchased a new software which may be able to detect the changes in the biomechanical values after $C X L$. O ur results confirm the study of Dauwe et $\mathrm{al}^{23}$ which demonstrated that intrastromal rings implantation did not al ter the viscoelastic biomechanical parameters of $\mathrm{CH}$ and $\mathrm{CRF}$.

\section{CONCLUSION}

The combined treatment of Intacs SK and CXL for the treatment on keratoconus is safe and effective in improving vision of advanced and even very thin keratoconic eyes. It is another tool to face keratoconus challenges. Further studies are needed to evaluate the long-term efficacy and results of this combined treatment.

\section{REFERENCES}

1. Schanzlin DJ,A sbell PA, B urris TE, D urrie DS. The intrastromal corneal ring segments; phase II results for the correction of myopia. O phthalmology 1997;104:1067-78.

2. Colin J. European clinical evaluation: U se of Intacs for the treatment of keratoconus. J Cataract R efract Surg 2006; 32:74755.

3. Colin J, Cochener B, Savary G, M alet F. Correcting keratoconus with intracorneal rings. J Cataract Refract Surg 2000;26:1117-22.

4. Colin J, Cochener B, Savary G, M alet F, Holmes-Higgin D. Intacs inserts for treating keratoconus; 1-year results. Ophthalmology 2001;108:1409-14.

5. B oxer W achler BS, Chandra NS, Chou B, K orn TS, N epomuceno R, Christie JP. Intacs for keratoconus. Ophthalmology 2003; 110:1031-40; errata, 1475.

6. Siganos CS, Kymionis GD, K artakis N, Theodorakis M A, A styrakakis N, Pallikaris IG. M anagement of keratoconus with Intacs. A m J O phthalmol 2003;135:64-70.

7. Hellstedt T, M äkelä J, U usitalo R, Emre S, U usitalo R. Treating keratoconus with Intacs corneal ring segments. J Refract Surg 2005;21:236-46.

8. L evinger S, Pokroy R. K eratoconus managed with Intacs; 1 year results. A rch Ophthal mol 2005;123:1308-14.

9. Colin J, M alet FJ. Intacs for the correction of keratoconus: Two year follow-up. J Cataract R efract Surg 2007;33:69-74.

10. Kymionis GD, Siganos CS, K ounis G, et al. M anagement of post-L asik corneal ectasia with Intac inserts: One year results. A rch O phthal mol 2003;121:322-26.

11. L uís A Rodríguez, A nny E Villegas, Dianela Porras, María A Benavides, Javier M olina. Treatment of six cases of advanced ectasia after lasik with 6-mm Intacs SK. J Refract Surg 2009 Dec;25(12):1116-19. 
12. Sansanayudh W, B ahar I, K umar N L, Shehadeh-M ashour R, Ritenour R, Singal N, R ootman DS. Intrastromal corneal ring segment SK implantation for moderate to severe keratoconus. J Cataract R efract Surg 2010 J an;36(1):110-13.

13. Wollensak G, Spoerl E, Seiler T. Riboflavin/UItraviolet-A induced collagen cross-linking for the treatment of keratoconus. A m J Ophthalmol 2003;135:620-27.

14. Ertan A, Karacal H, K amburoðlu G. R efractive and topographic results of transepithelial cross-linking treatment in eyes with Intacs. Cornea 2009 A ug;28(7):719-23.

15. Alió JL, Shabayek MH, Belda JI, Correas P, Feijoo ED. A nalysis of results related to good and bad outcomes of Intacs implantation for keratoconus correction. J Cataract R efract Surg $2006 \mathrm{M}$ ay;32(5):756-61.

16. Chan CK, Sharma M , B rian S. Effect of inferior-segment Intacs with and without $\mathrm{C} 3-\mathrm{R}$ on keatoconus. Boxer Wachler Colin 2007;33(1):75-80.

17. Ertan A, Colin J. Intracorneal rings for keratoconus and keratectasia. J Cataract Refract Surg 2007 J ul;33(7):1303-14.

18. Kamburoglu G, Ertan A. Intacs implantation with sequential collagen cross-linking treatment in postoperative L asik ectasia. J Refract Surg 2008 Sep;24(7):S726-29.

19. Coskunseven $E$, Jankov M R 2nd, Hafezi F, A tun S, A rslan E, Kymionis GD. Effect of treatment sequence in combined intrastromal corneal rings and corneal collagen cross-linking for keratoconus. J Cataract R efract Surg 2009 Dec;35(12):2084-91.

20. Liu R, ChuRY, Zhou XT, Qu XM , Dai JH, W ang L. A compare study on cornea biomechanical properties in normal and keratoconic eyes. Zhonghua Y an Ke Za Zhi 2009 J un;45(6):509-13.
21. Ortiz D, Piñero D, Shabayek M H, A rnalich-M ontiel F, Alió JL. Corneal biomechanical properties in normal, post-laser in situ keratomileusis, and keratoconic eyes. J Cataract R efract Surg 2007 A ug;33(8):1371-75.

22. Shah S, Laiquzzaman M, Bhojwani R, M antry S, Cunliffe I. A ssessment of the biomechanical properties of the cornea with the ocular response analyzer in normal and keratoconic eyes. Invest Ophthalmol V is Sci 2007 Jul;48(7):3026-31.

23. Dauwe $C$ Touboul $D$, Roberts $C$ J, M ahmoud $A M, K$ érautret $]$, Fournier $P$, M alecaze $F$, et al. Biomechanical and morphological corneal response to placement of intrastromal corneal ring segments for keratoconus. J Cataract Refract Surg 2009 Oct;35(10):1761-67.

\section{ABOUT THE AUTHORS}

\section{Ramez Barbara (Corresponding Author)}

Department of O phthalmology, B nai Zion M edical Center, 47 Golomb Street, Haifa-31048, Israel, Phone: +972524448687, Fax: +97249815911 e-mail: ramezborbara@gmail.com

\section{Hanna Garzozi}

Department of O phthal mology, B nai Zion M edical Center, Haifa, Israel

\section{Adel Barbara}

Department of Ophthalmology, Hadassah Optimal Medical Center Haifa, Israel 